\title{
Analysis of Polyhydroxyalkanoates Granules in Haloferax mediterranei by Double-Fluorescence Staining with Nile Red and SYBR Green by Confocal Fluorescence Microscopy
}

\author{
Verónica Cánovas 1,2,*(D), Salvador Garcia-Chumillas ${ }^{1,2}$, Fuensanta Monzó ${ }^{1}$, Lorena Simó-Cabrera ${ }^{3,4} \mathbb{D}$, \\ Carmen Fernández-Ayuso ${ }^{1}$, Carmen Pire ${ }^{3,4}$ and Rosa María Martínez-Espinosa ${ }^{3,4, *}$ (D) \\ 1 Technological Centre of Footwear and Plastic of the Region of Murcia (CETEC) Avda, Europa 4-5, \\ 30840 Alhama de Murcia, Spain; schumillas@gmail.com (S.G.-C.); f.monzo@ctcalzado.org (F.M.); \\ c.fernandez@ctcalzado.org (C.F.-A.) \\ 2 Cetec Biotechnology, Avda, Europa 4-5, 30840 Alhama de Murcia, Spain \\ 3 Department of Agrochemistry and Biochemistry, Biochemistry and Molecular Biology Division, \\ Faculty of Science, University of Alicante, Carretera San Vicente del Raspeig s/n, San Vicente del Raspeig, \\ 03690 Alicante, Spain; lorena.simo@ua.es (L.S.-C.); carmen.pire@ua.es (C.P.) \\ 4 Multidisciplinary Institute for Environmental Studies "Ramón Margalef", University of Alicante, Ap. 99, \\ 03080 Alicante, Spain \\ * Correspondence: v.canovas@ctcalzado.org (V.C.); rosa.martinez@ua.es (R.M.M.-E.); \\ Tel.: +34-968-662-200 (V.C.); +34-965-903-400 (ext. 1258) (R.M.M.-E.)
}

Citation: Cánovas, V.;

Garcia-Chumillas, S.; Monzó, F.; Simó-Cabrera, L.; Fernández-Ayuso, C.; Pire, C.; Martínez-Espinosa, R.M. Analysis of Polyhydroxyalkanoates Granules in Haloferax mediterranei by Double-Fluorescence Staining with Nile Red and SYBR Green by Confocal Fluorescence Microscopy. Polymers 2021, 13, 1582. https:// doi.org/10.3390/polym13101582

Academic Editor: Beom Soo Kim

Received: 12 April 2021

Accepted: 12 May 2021

Published: 14 May 2021

Publisher's Note: MDPI stays neutral with regard to jurisdictional claims in published maps and institutional affiliations.

Copyright: (c) 2021 by the authors. Licensee MDPI, Basel, Switzerland. This article is an open access article distributed under the terms and conditions of the Creative Commons Attribution (CC BY) license (https:/ / creativecommons.org/licenses/by/ $4.0 /)$.
Abstract: Haloferax mediterranei is a haloarchaeon of high interest in biotechnology because it produces and mobilizes intracellular polyhydroxyalkanoate (PHA) granules during growth under stress conditions (limitation of phosphorous in the culture media), among other interesting metabolites (enzymes, carotenoids, etc.). The capability of PHA production by microbes can be monitored with the use of staining-based methods. However, the staining of haloarchaea cells is a challenging task; firstly, due to the high ionic strength of the medium, which is inappropriate for most of dyes, and secondly, due to the low permeability of the haloarchaea S-layer to macromolecules. In this work, Haloferax mediterranei is used as a halophilic archaeon model to describe an optimized protocol for the visualization and analysis of intracellular PHA granules in living cells. The method is based on double-fluorescence staining using Nile red and SYBR Green by confocal fluorescence microscopy. Thanks to this method, the capability of PHA production by new haloarchaea isolates could be easily monitored.

Keywords: haloarchaea; Haloferax mediterranei; polyhydroxyalkanoates (PHAs); Nile red; SYBR Green; confocal microscopy; transmission electronic microscopy

\section{Introduction}

Polyhydroxyalkanoates (PHAs) are biopolymers produced and accumulated in many prokaryotic microbes (bacteria or archaea) as carbon and energy storage materials, ensuring their survival under stress conditions [1]. Typically, PHA biosynthesis is favored by limiting an essential nutrient—such as nitrogen, phosphorous, or oxygen-for microbial growth, with a parallel high availability of an exogenous carbon source [2]. They are water insoluble polymers and stored in the cell cytoplasm as granules. PHAs are biodegradable, biocompatible, and thermoplastic polymers, and due to these features, they have recently attracted increasing attention for their industrial application in the production of biodegradable plastic used for packaging or in the biomedical field [3,4].

In this context, extremophilic microbes in general, and particularly the haloarchaea group (Archaea domain), have attracted the attention of the scientific community due to their peculiar metabolic capabilities. In addition to the applicability in bioplastic production shown by some species, their adaptations to extreme environments make the haloarchaea a 
promising source of different biocompounds of high interest in biotechnology and biomedical applications $[5,6]$. For instance, carotenoids such as bacterioruberin and lycopene with a high antioxidant activity, as well as extracellular polymeric substances (EPS), mainly composed of polysaccharides and exhibiting high viscosity, are suitable natural additives in the food, pharmaceutical, and cosmetic industries [7]. Moreover, other biocompounds and biomolecules of significant interest are gas vesicles, which are protein-based buoyancy organelles produced by some halophilic archaea with a potential role in immunology for the generation of vaccines due to their role as scaffolds during the presentation of epitopes [6]; ether-linked lipids as novel drug delivery systems [8]; bacteriorhodopsin, a photochemical material for bioelectronics and photochemical processes [5]; and enzymes with high activity and stability at high temperatures, and high ionic strength in industrial applications [9].

Haloferax mediterranei is one of the better-described haloarchaea at the time of writing this work. It is an extreme halophilic capable of accumulating poly(3-hydroxybutyrateco-3-hydroxyvalerate) (PHBV) from many cheap carbon sources [10-14]. The key enzyme involved in the biosynthesis of PHA in haloarchaea is PHA synthase, which catalyses the polymerization of the hydroxyalkanoate monomer to produce PHA chains. PHA synthase in haloarchaea consists of two subunits, PhaC and PhaE, and belongs to class III [15-17]. Apart from this enzyme, two other proteins are essential for PHA synthesis in haloarchaea-a 3-ketoacyl-acyl carrier protein reductase (PhaB) and a structural protein called PHA granule-associated protein (PhaP), which is involved in polyhydroxyalkanoate accumulation and granule formation [18]. The main advantage of using haloarchaea as cell factories to produce PHAs as compared to bacteria is that haloarchaeal cultures on a moderate or large scale do not need strict sterile conditions due to the high concentrations of salt needed by the cells to stay alive. This makes cultivation easier and more convenient as compared to eubacterial strains. Besides, raw materials like brines could even be used to prepare the culture media for these strains, thus contributing to the circular economy processes $[7,19]$. Hence, haloarchaea are revealed as a promising natural source for bioplastic production in an attempt to reduce global contamination caused by plastic production and microplastic accumulation [20,21].

Different approaches have been used for the screening of PHA-producing microbes and/or the imaging of PHA granules [22-26]. The main aim of these approaches is to quickly identify, at low cost and from a biotechnological point of view, the capability of new isolates of microbes of high interest to produce PHAs. From among those approaches, transmission electron microscopy (TEM) is an excellent tool for imaging PHA granules [27] However, it is not useful for screening living PHA-producing cells. In addition, it is a labor-intensive, expensive, and time-consuming technique that needs highly experienced and skilled staff. Easy and rapid approaches based on cellular staining can be used to determine whether the cells are able to produce PHAs. Most extended protocols in bacteria include the use of lipophilic dyes such as Sudan black B, Nile blue A, and Nile red $[23,25,28,29]$. While the staining of cells with Sudan black B and Nile blue A requires heat-fixed cells, Nile red (which is a highly fluorescent and photostable organic dye with a greater affinity for PHAs than Sudan black B) allows the staining of living cells under growing conditions $[24,26]$. Due to their lipophilic nature, Nile blue A and Nile red staining are very useful for visualizing PHA granules, which are surrounded by a lipid membrane, thus appearing as bright fluorescent red granules $[24,30]$. Nile red has been widely used for the in vivo screening and identification of PHA-producing bacteria on agar plates through the observation of fluorescent colonies under UV light $[23,24,26]$. However, due to the lipophilic nature of Nile red and Nile blue A, they can occasionally bind unspecifically to other lipid inclusions, membranes, or cell envelopes and can lead to ambiguous results [31,32]. For this reason, staining with an additional fluorescence dye can be appropriate to co-localize PHA granules.

Fluorescence staining in halophilic microbes can be challenging. Firstly, this is due to the high ionic strength of the medium, which can be inappropriate for most of dyes 
(the removal of salt crystals is often difficult or even impossible, thus negatively affecting the final quality of the images); secondly, particular characteristics of archaea, including differences in cell membrane lipids and cell walls may hinder staining [33,34]. In contrast to bacteria, all archaea possess cell walls lacking peptidoglycan, the glycerol linkage between the phospholipid head, and the side chain is in the L-isomeric form instead of the Disomeric form; furthermore, membrane lipids present ether linkages as opposed to the ester-linked lipids found in bacteria and eukaryotes, thus providing more chemical stability to the membrane [34,35]. Moreover, a paracrystalline protein surface layer (S-layer) is generally present in nearly all archaea, reducing the permeability to macromolecules [33]. These limitations can explain the scarce number of works reporting the use of Nile red staining in haloarchaea for the visualization of PHA granules [31]. In this work, a rapid and easy method based on a double-fluorescence staining method is described for the first time in its identification and analysis of PHA granules in unfixed Hfx. mediterranei cells with the use of confocal microscopy. SYBR Green is a green fluorescent cyanine dye that has a high affinity for double-stranded DNA, but also for single-stranded DNA and RNA, although with less intensity $[36,37]$. The mode of binding is believed to be a combination of DNA intercalation and external binding. In this article, we show that double-staining with SYBR Green I and Nile red is compatible with high ionic-strength media and is useful for colocalizing PHA granules within the cytoplasm of living haloarchaea cells, thus improving the analysis of the granules (size and shapes) and their location within the cytoplasm.

\section{Materials and Methods}

\subsection{Cell Culture}

The Haloferax mediterranei strain R-4 (ATCC33500), previously isolated by RodríguezValera et al. (1980) from saltern ponds located in Santa Pola, Alicante, Spain, was used for all experiments [38]. The growth medium was adapted from Lillo and Rodriguez-Valera (1990) [39] and contained (g/L) (minimal medium): $194.9 \mathrm{~g} \mathrm{NaCl} ; 49.4 \mathrm{~g} \mathrm{MgSO}_{4} \cdot 7 \mathrm{H}_{2} \mathrm{O}$; $34.6 \mathrm{~g} \mathrm{MgCl}_{2} \cdot 6 \mathrm{H}_{2} \mathrm{O} ; 5.0 \mathrm{~g} \mathrm{KCl} ; 0.17 \mathrm{~g} \mathrm{NaHCO}_{3} ; 0.58 \mathrm{~g} \mathrm{NaBr} ; 0.92 \mathrm{~g} \mathrm{CaCl}_{2} ; 0.005 \mathrm{~g} \mathrm{FeCl}_{3}$; $1 \mathrm{~g} \mathrm{KNO}_{3}$ as nitrogen source; $0.25 \mathrm{~g} \mathrm{NaH}_{2} \mathrm{PO}_{4}$ as phosphorus source; and $10 \mathrm{~g}$ of glucose as carbon source (PanReac AppliChem, Darmstadt, Germany) at $\mathrm{pH} 7.2$ [16]. The $\mathrm{pH}$ level was first adjusted with $\mathrm{NaOH} 1 \mathrm{~N}$. Hfx. mediterranei cells were diluted in a growth medium to an initial optical density of approximately 0.20 at $600 \mathrm{~nm}\left(\mathrm{OD}_{600 \mathrm{~nm}}\right)$ (with growth medium used for blank). An amount of $100 \mathrm{~mL}$ of cell cultures was developed in $500 \mathrm{~mL}$ flasks at $42{ }^{\circ} \mathrm{C}$, in a horizontal incubator (BioSan, Riga, Latvia) with a shaking platform (170 rpm).

\subsection{Sample Preparation and Fluorescence Staining}

After approximately $72 \mathrm{~h}$ of incubation, $10 \mathrm{~mL}$ of cell culture at the late exponential growth phase $\left(\mathrm{OD}_{600 \mathrm{~nm}}=1.50\right)$ were transferred to a new $50 \mathrm{~mL}$ flask and used for Nile red staining. The other $90 \mathrm{~mL}$ of the cell culture were kept in incubation for further TEM analysis and PHA extraction. Nile red (Sigma-Aldrich, Darmstadt, Germany, cat. number N3013) was dissolved in methanol to obtain a $500 \mu \mathrm{g} / \mathrm{mL}$ stock solution. The solution was stored at $4{ }^{\circ} \mathrm{C}$ for 1 month. To stain $H f x$. mediterranei cells, the Nile red stock solution was added to the $10 \mathrm{~mL}$ of the growth medium at a 1:1000 dilution (to a final concentration of $0.5 \mu \mathrm{g} / \mathrm{mL}$ ) and cells were cultured in a $50 \mathrm{~mL}$ flask for $24 \mathrm{~h}$ at $42{ }^{\circ} \mathrm{C}$, under shaking conditions $(170 \mathrm{rpm})$. After this incubation time $\left(\mathrm{OD}_{600 \mathrm{~nm}}=1.95\right)$, the cells stained with Nile red were harvested by centrifugation at $3000 \times g$ for $15 \mathrm{~min}$ and washed twice with a saline buffer $(10 \% \mathrm{NaCl}, 0.1 \mathrm{M}$ sodium phosphate buffer, $\mathrm{pH} 7.2)$. The pellet was resuspended in $100 \mu \mathrm{L}$ of the saline buffer and $2 \mu \mathrm{L}$ of SYBR Green (dsGreen 100X qPCR, Canvax Biotech, Córdoba, Spain) were added to the $1.5 \mathrm{~mL}$ Eppendorf tube containing Nile red-stained cells, mixed by vortexing and incubated in the dark at room temperature for $15 \mathrm{~min}$. The cells were washed with the saline buffer, collected by centrifugation at $3000 \times g$ for $15 \mathrm{~min}$, and resuspended in $100 \mu \mathrm{L}$ of the saline buffer for further confocal microscopy analysis. 


\subsection{Confocal Fluorescence Microscopy}

For fluorescence and phase contrast microscopy, a drop of the previous sample (stained cells resuspended in saline buffer) was pipetted in a slide. Then, cells were covered with a cover slip and edges of the cover slip were sealed with nail polish. The cells were imaged with a confocal microscope Leica TCS SP8 (Leica Microsystems, Wetzlar, Germany) using an HC PL APO CS2 63x/1.3 Glycerol objective, in a $1024 \times 1024$ format, at $400 \mathrm{~Hz}$ scan speed and hybrid detectors (HyD). The cells were excited by $553 \mathrm{~nm}$ Ar-laser for Nile red and by $497 \mathrm{~nm}$ Ar-laser for SYBR Green and detected with a Leica HyD hybrid detector (569nm-648nm). All images were processed using LAS X 3.5.5.19976 (Leica) and ImageJ Fiji vl.50c.

\subsection{Transmission Electron Microscopy (TEM)}

After $96 \mathrm{~h}, 20 \mathrm{~mL}$ of the cell culture in the stationary phase $\left(\mathrm{OD}_{600 \mathrm{~nm}}=1.95\right)$ were harvested by centrifugation at $3000 \times g$ for $15 \mathrm{~min}$ for the TEM analysis. The cells were washed twice with a saline buffer $(10 \% \mathrm{NaCl}, 0.1 \mathrm{M}$ sodium phosphate buffer, $\mathrm{pH} 7.2)$, resuspended in a $2.5 \%(v / v)$ glutaraldehyde solution prepared in saline buffer for primary fixation overnight at $4{ }^{\circ} \mathrm{C}$. Following the primary fixation, the cells were pelleted and washed three times with a saline buffer. The cell pellets were then fixed with $1.0 \%$ osmium tetroxide in SP buffer $(1 \% v / v)$ for $2 \mathrm{~h}$ at $4{ }^{\circ} \mathrm{C}$ and subsequently washed three times with a saline buffer. A third fixative solution was added to the cells, $0.5 \%(w / v)$ uranyl acetate solution (in Veronal-acetate buffer) and cells were incubated overnight in the dark at $4{ }^{\circ} \mathrm{C}$. The ensuing steps were performed according to the procedure described by Tian et al. (2005) [40]. Photomicrographs were taken with a Philips Tecnai 12 Electron Microscope (Carl Zeiss, Oberkochen, Germany), capable of imaging negatively stained samples at voltages ranging between $80 \mathrm{Kv}$ and $120 \mathrm{Kv}$, equipped with a megaview III digital camera.

\subsection{Determination of Cell Dry Weight (CDW) and PHBV Extraction and Purification}

After fermentation, the rest of the cell culture (approximately $70 \mathrm{~mL}$ ) was harvested by centrifugation at $3000 \times g$ for $15 \mathrm{~min}$. Then, the cells were washed with a $10 \% w / v \mathrm{NaCl}$ solution and were centrifuged again to remove debris. The cell pellet was resuspended in deionized water with $0.1 \%$ sodium dodecyl sulfate (SDS) to achieve hypo-osmotic shock and complete cells lysis and dried at $70{ }^{\circ} \mathrm{C}$ for at least $5 \mathrm{~h}$ and weighed to determine its CDW. The dry pellet was treated with hot chloroform at $90^{\circ} \mathrm{C}$ for $6 \mathrm{~h}$, followed by precipitation with 10 volumes of pre-chilled methanol. To collect PHAs, the precipitate was centrifuged at $4000 \times g$ for $25 \mathrm{~min}$ and PHAs were dried at $70{ }^{\circ} \mathrm{C}$ for $2 \mathrm{~h}$ to remove all residual solvent. The pellet, corresponding to raw PHBV, was recovered, and weighed. The polymer yield was calculated as [PHBV (g)/CDW (g)].

\subsection{Attenuated Total Reflectance-Fourier Transform Infrared (ATR-FTIR) Analysis}

Aliquots of the polymer were subjected to the ATR-FTIR analysis. The spectrum was recorded using a Spectrum Two FT-IR Spectrometer (Bruker Vertex 70-80, Billerica, MA, USA) from 400 to $4000 \mathrm{~cm}^{-1}$, with a resolution of $4 \mathrm{~cm}^{-1}$ and averaged over 32 scans.

\subsection{Statistics}

For the analysis of PHA granule size, the Image J Fiji free software was used to measure the diameter of PHA granules. Analysis of data was performed using GraphPad Prism 5 software and a $p$-value $<0.05$ was taken as the level of significance. The data are the means of three independent experiments \pm standard deviations $(n=3)$.

\section{Results}

\subsection{Nile Red Staining and Detection of PHA Granules by Confocal Microscopy}

Staining with Nile red was performed with the cells of a known producer of PHBV, Haloferax mediterranei, growing in an aqueous and high-salt-grown medium $(3.3 \mathrm{M} \mathrm{NaCl})$. Confocal fluorescence microscopy, at an excitation wavelength of $553 \mathrm{~nm}$, revealed nu- 
merous brightly fluorescent red granules within the cells corresponding to PHA granules (Figure 1). However, the identification of cells by phase contrast microscopy for the localization of PHA granules inside the cells $[26,31,41,42]$ is not a suitable technique for haloarchaea due to the high concentration of salts in the culture medium as well as in the cytoplasm, making the image quality not optimal due to the presence of salt crystals (Figure 1).
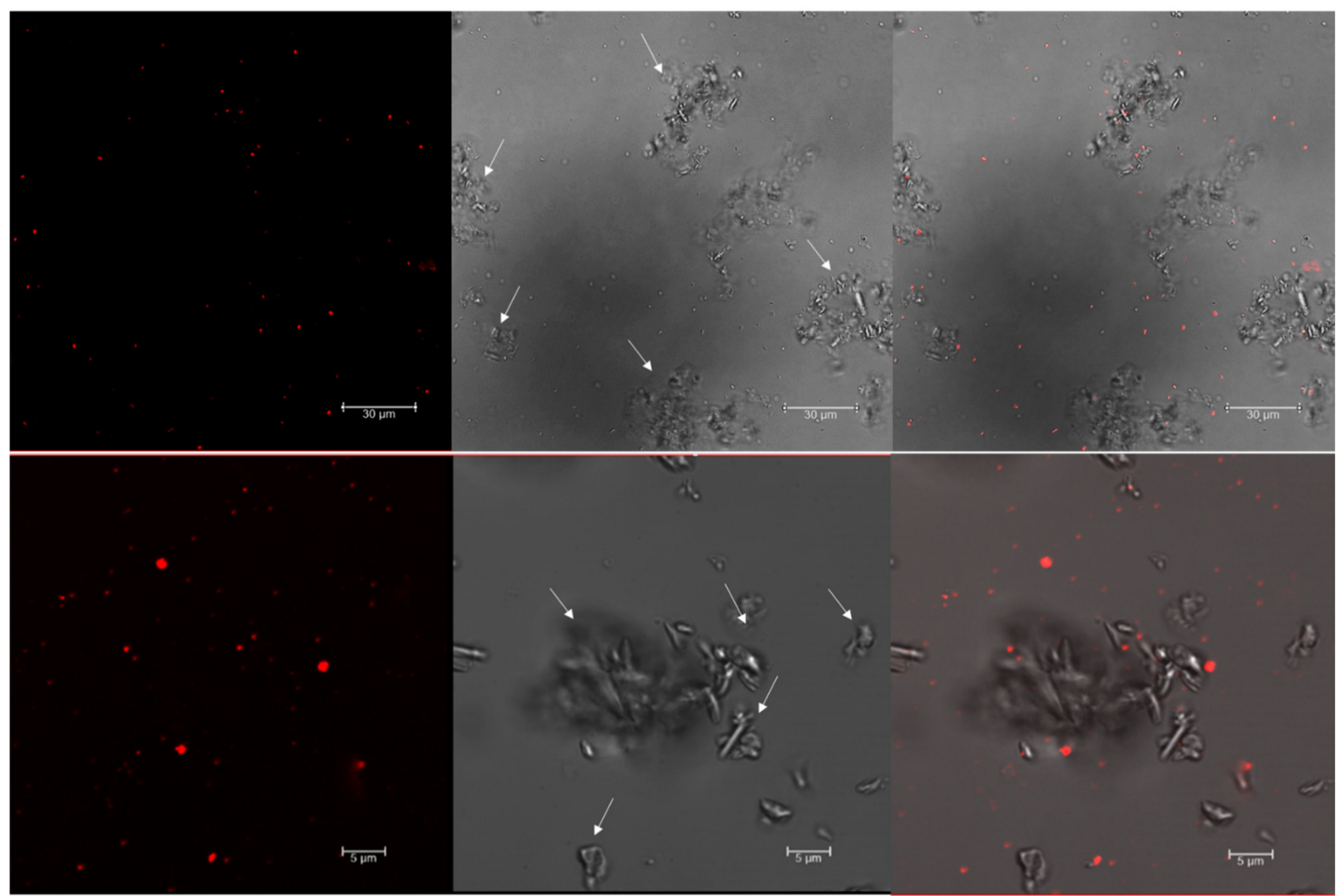

Figure 1. Confocal images of Nile red-stained Haloferax mediterranei cells. The Hfx. mediterranei cells in the stationary phase were stained with Nile red $(0.5 \mu \mathrm{g} / \mathrm{mL})$ and imaged with a confocal microscope 4 days after subculture. Arrows point to crystals of mineral salts. From left to right: red fluorescence PHA granules; phase contrast image; overlay image of red fluorescence and phase contrast image.

To avoid interference in the identification of the cells and the co-localization of the PHA granules inside the cells due to the presence of salt crystals on microscopy, the cells were stained using Nile red and SYBR Green dyes (as described in Materials and Methods) and observed using confocal fluorescence microscopy (Figure 2). As mentioned above, fluorescence microscopy at an excitation wavelength of $553 \mathrm{~nm}$ revealed numerous brightly fluorescent red granules within the cells, corresponding to PHA granules. An excitation wavelength of $497 \mathrm{~nm}$ revealed fluorescent green spots corresponding to stained DNA in the cytoplasm of cells. Merged images confirmed the intracellular co-localization of PHA granules in the cytoplasm of cells, which would otherwise be complicated due to the presence of salts in the medium masking cells and low-resolution contrast phase images (Figure 2). TEM pictures of the same culture confirmed the presence of PHA granules (Figure 3). 

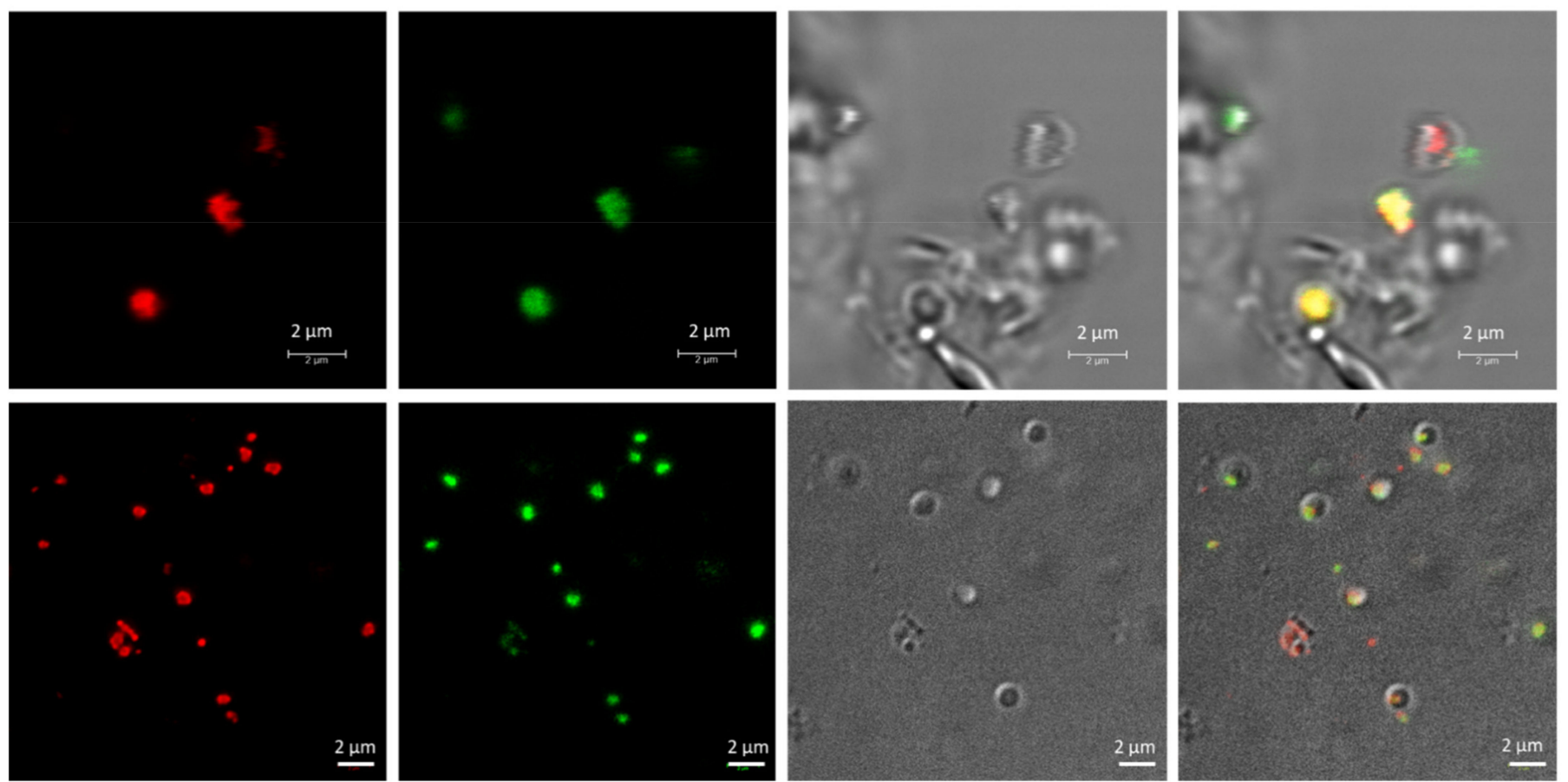

Figure 2. Fluorescence confocal micrographs of living Haloferax mediterranei cells, with PHA granules stained with Nile red and SYBR Green. Unfixed Hfx. mediterranei cells were co-stained with Nile red lipid fluorescence dye and the nucleic acid-staining dye SYBR Green, revealing the intracellular co-localization of PHA granules with numerous DNA spots in the cytoplasm of the cell, as visualized during confocal microscopy. From left to right: Nile red, SYBR Green, phase contrast and merged channels of Nile red, SYBR Green, and phase contrast images.
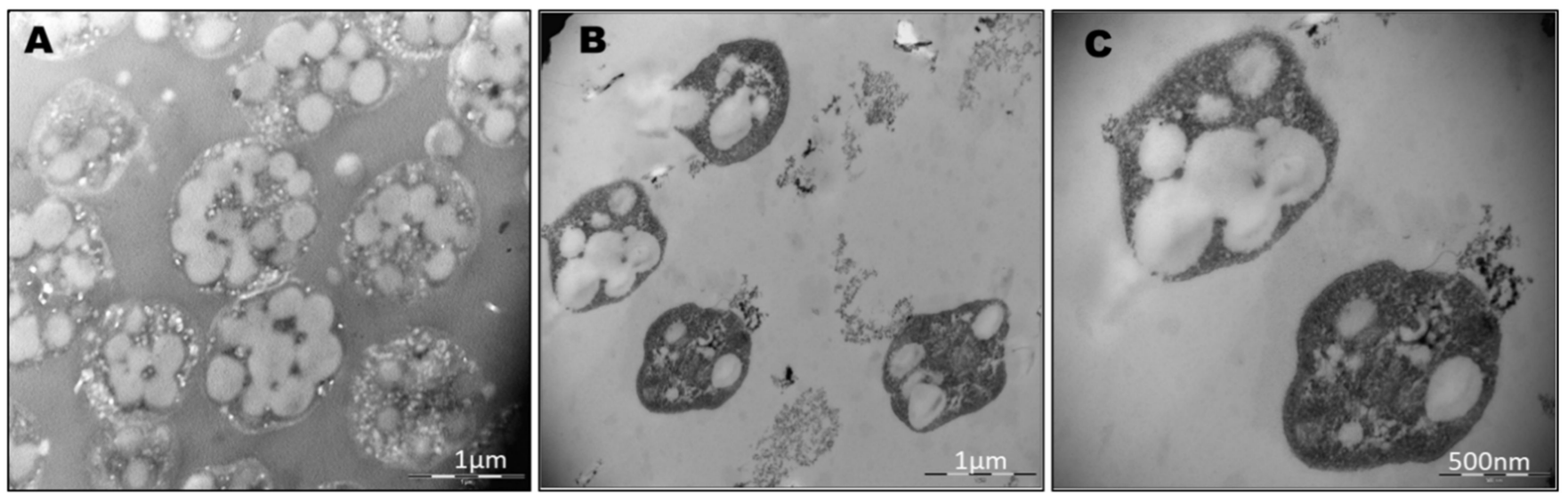

Figure 3. Electron micrograph of ultra-thin sections of Haloferax mediterranei. (A), (B), and (C) show electron micrographs of Hfx. mediterranei cells demonstrating the accumulation of PHA granules. Cells were cultured at $42{ }^{\circ} \mathrm{C}$ for $96 \mathrm{~h}$ in a phosphorous-limited medium.

\subsection{Analysis of PHA Granules Size}

Double staining with Nile red and SYBR Green allows the visualization of PHA granules in high resolution and the precise co-localization of PHA granules in the cytoplasm of Hfx. mediterranei cells (Figure 4A). The size of the PHA granules ranged from approximately 150 to $450 \mathrm{~nm}$, as analyzed in the confocal images (Figure 4B). Similar results were obtained when TEM micrographs were used to analyze PHA granule size (Figure 4C,D), confirming that fluorescence co-staining of $H f x$. mediterranei cells with Nile red and SYBR Green can be a useful and rapid approach in visualizing and analyzing PHA granule size. 
A

Nile red
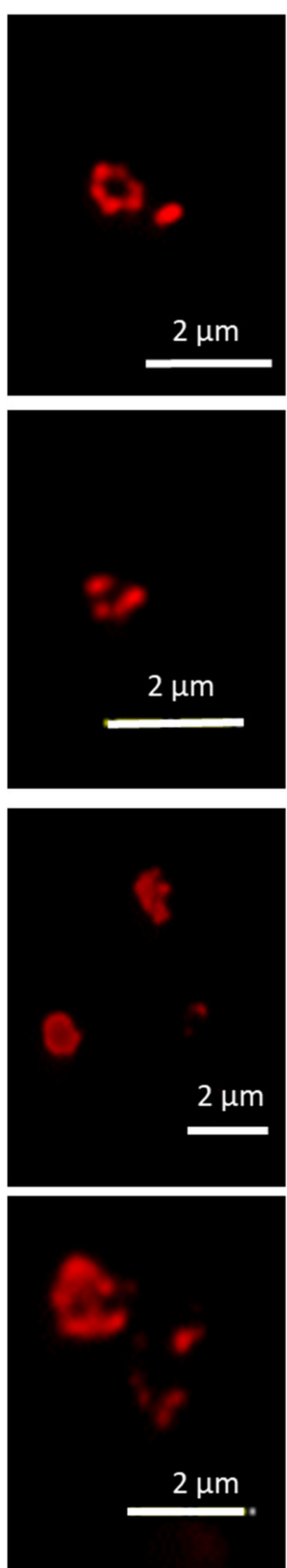

SYBR Green
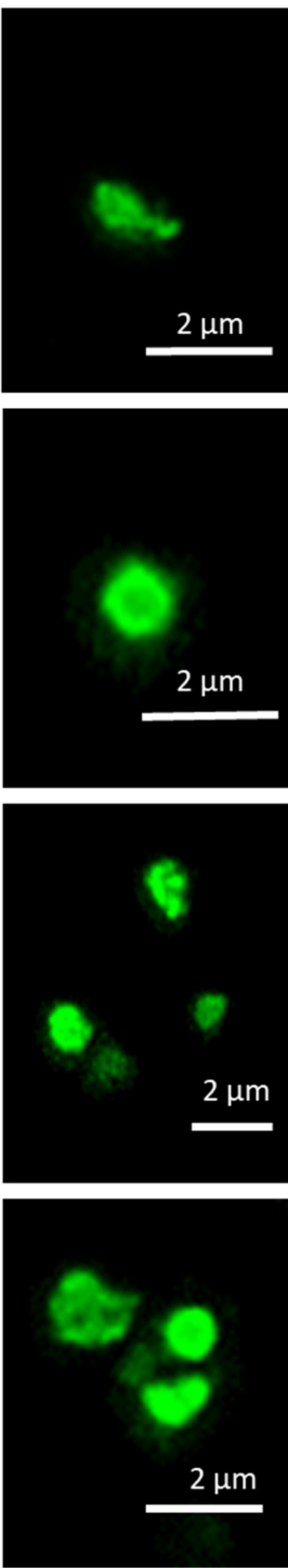

B

Merged
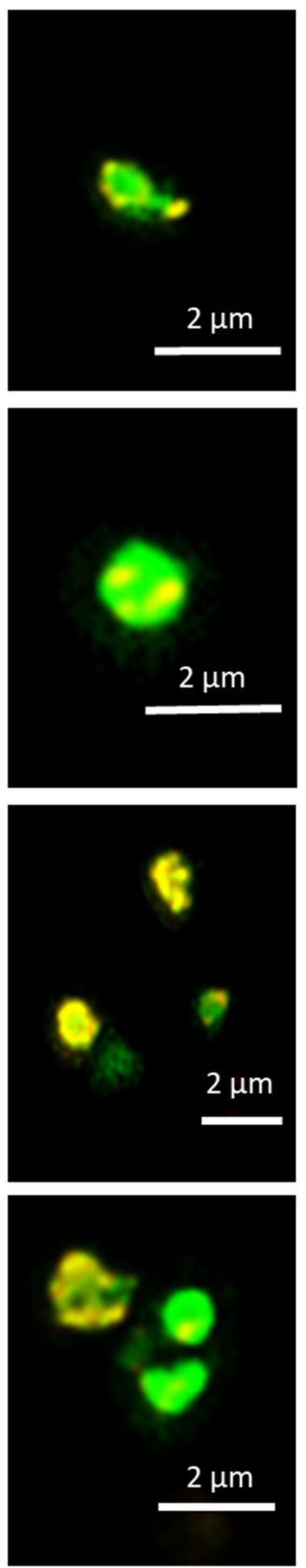

\section{$\mathrm{CM}$}

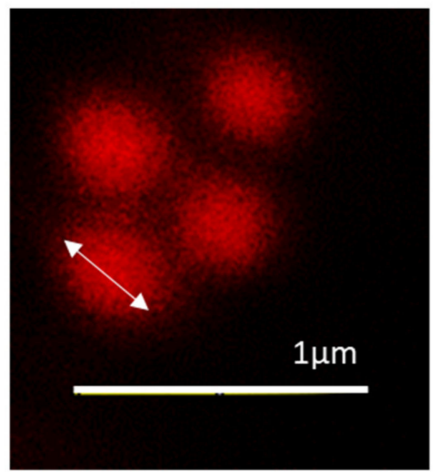

TEM

C

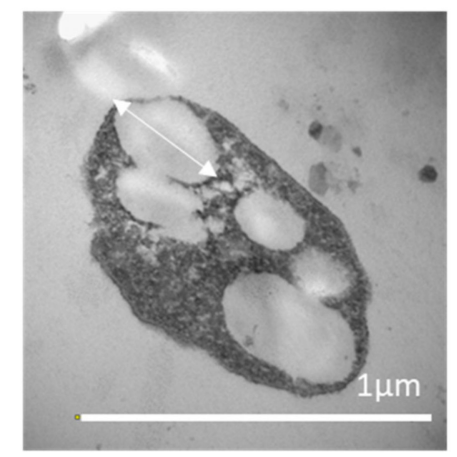

D

\section{PHA granules size}

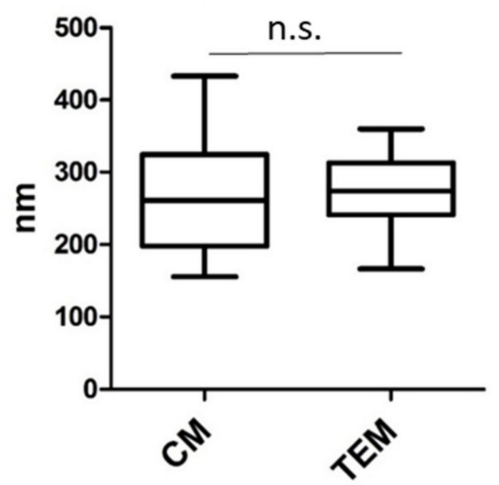

Figure 4. Analysis of PHA granule size stained with Nile red by confocal microscopy in living Haloferax mediterranei cells. (A) Unfixed $H f x$. mediterranei cells were co-stained with Nile red lipid fluorescence dye and the nucleic acid-staining dye SYBR Green, revealing the intracellular co-localization of PHA granules with numerous DNA spots in the cytoplasm of the cell as visualized during confocal microscopy. From left to right: Nile red, SYBR Green, and merged channels of Nile red and SYBR Green. (B) Image of PHA granules taken by confocal microscopy (CM). (C) Image of PHA granules taken by transmission electron microscopy (TEM). (D) Box and whisker plot represents PHA granule size (CM n = 14 and TEM $\mathrm{n}=16$ ). Image J software was used to measure PHA granule size, and data were plotted and analyzed with GraphPad Prism 5 software. Non-significant differences in granule size were found after comparing the two methods $(p=0.979)$. 


\subsection{PHA Extraction and Polymer Characterization by ATR-FTIR Spectroscopy}

The capabilities of Hfx. mediterranei to accumulate PHAs were evaluated at the shaking flask level in a phosphorous-limited medium with $10 \mathrm{~g} / \mathrm{L}$ glucose. After $96 \mathrm{~h}$ of incubation at $42{ }^{\circ} \mathrm{C}$, the PHBV synthesis corresponded to $0.198 \pm 0.06 \mathrm{~g} / \mathrm{L}$ (Table 1). The polymer extraction confirms the presence of PHA granules.

Table 1. CDW, PHBV production and yield obtained after $96 \mathrm{~h}$ of fermentation in a shaken flask. SD = standard deviation. All data are expressed as the mean \pm SD of three independent experiments.

\begin{tabular}{cllcc}
\hline Strain & Carbon Source & CDW (g/L) & PHA (g/L) & Yield (PHA/CDW) g g $^{-1}$ \\
\hline $\begin{array}{c}\text { Haloferax mediterranei } \\
\text { R-4 (ATCC33500) }\end{array}$ & Glucose $10 \mathrm{~g} / \mathrm{L}$ & $2.31 \pm 0.26$ & $0.198 \pm 0.06$ & $0.084 \pm 0.02$ \\
\hline
\end{tabular}

The purified polymer was analyzed by the FTIR spectrophotometer with ATR and compared with a commercial PHBV (Figure 5). The FTIR spectra of both samples showed an absorption peak near $1721 \mathrm{~cm}^{-1}$, which corresponds to the ester carbonyl bond $(\mathrm{C}=\mathrm{O})$, the most important feature of the copolymer 3-hydroxybutyrate-co-3-hydroxyvalerate (PHBV) [43]. Other absorption bands for the polymer sample obtained under the conditions of this study (Figure 5) were found in the range $2924-2856 \mathrm{~cm}^{-1}\left(\mathrm{CH}, \mathrm{CH}_{2}\right.$ symmetric and asymmetric stretching), $1450-1380 \mathrm{~cm}^{-1}$ (C-C stretching), at $1132 \mathrm{~cm}^{-1}$ (C-O stretching), and in the range $978-821 \mathrm{~cm}^{-1}$ corresponding to C-C deformation [10]. The spectra corresponded to the typical profile of a copolymer PHBV, previously reported in Hfx. mediterranei [16].

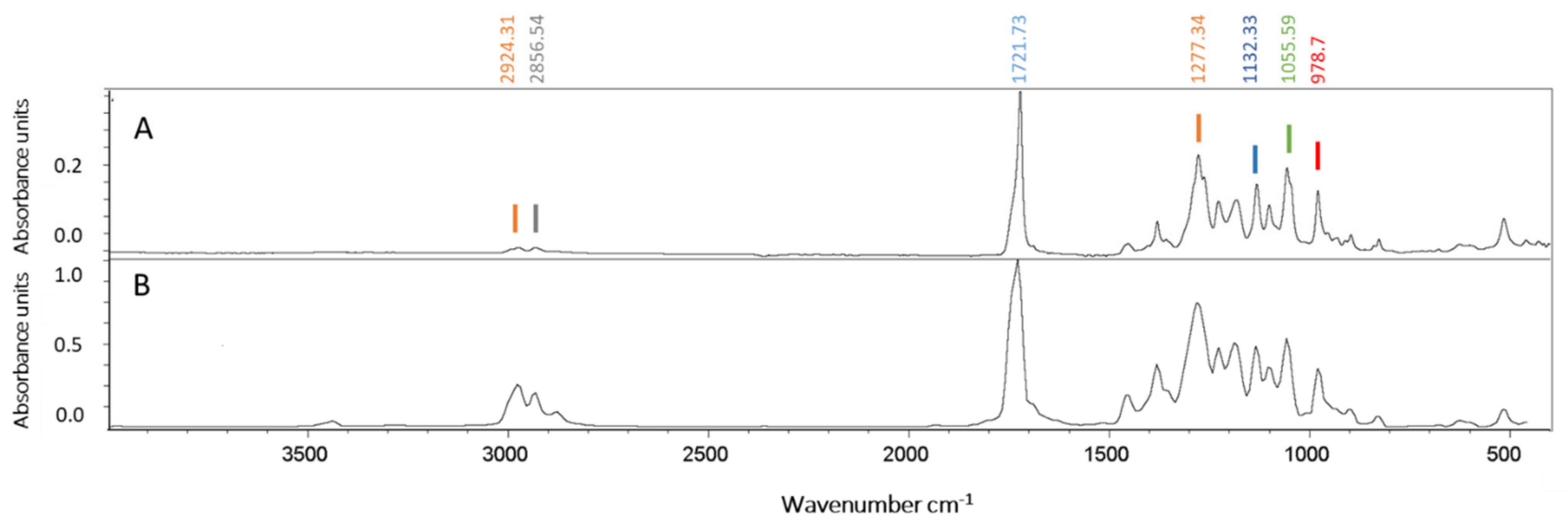

Figure 5. Polymer characterization by ATR-FTIR spectroscopy. Attenuated total reflectance-Fourier transform infrared (ATR-FTIR) spectra of the PHBV purified from Hfx. mediterranei (panel A) and of the commercial reference Sigma Aldrich PHBV with a PHV content of $12 \mathrm{~mol} \%$ (cas number 80181-31-3) (panel B).

\section{Discussion}

As highlighted in the introduction of this article, haloarchaea have emerged as promising and valuable biotechnological platforms for the production of compounds of high interest in the industry; these are compounds such as carotenoids, EPS, ether-linked lipids, and PHAs amongst others $[6,7,13]$. Haloarchaeal cultivation is easier and more convenient compared to eubacterial strains-its low requirement for sterile conditions results from the high concentrations of salt needed by the cells to stay alive [10,12,14]. Furthermore, cell walls and membranes of haloarchaea are easy to lyse by osmotic shock with the use of distilled water, as demonstrated in this work. This allows for the recovery of PHBV granules with the use of fewer chemicals and in a much easier and more economical way $[6,10,14]$. Particularly, most haloarchaea, including Hfx. mediterranei, can synthesize the copolymer PHBV even without any external precursor, as confirmed by ATR-FTIR 
analysis in this work (Figure 5 and Table 1); moreover, they contribute to reducing the production costs $[44,45]$. Furthermore, raw materials like brines could even be used to prepare culture media for these strains, thus contributing to circular economy processes [46]. These advantages constitute an important aspect to consider when designing large-scale biotechnological approaches that allow for the reduction of production costs. Consequently, extremophiles have recently been identified as one of the most promising microorganisms to produce PHA, which reduce production costs [47].

Studies of screening methods for the presence and characterization of PHAs in archaea, and especially in haloarchaea, using fluorescent dyes such as Nile red are scarce. Like bacteria, archaea possess a cell wall that protects the cell from the environment, though their membranes differ from those of bacteria and other organisms in different aspects. Archaea cell walls possess ether linkages instead of ester linkages; they are composed of regularly branched phytanyl and biphytanyl chains instead of fatty acyl chains; the glycerol linkage between the phospholipid head and the side chain is in the L-isomeric form, while bacteria and eukaryotes have the D-isomeric form, and proteins also tend to be rich in surface-exposed negatively charged amino acids [33-35]. These properties contribute to the greater chemical stability of archaeal envelopes, but also to the low permeability of archaeal membranes, hindering staining. Most haloarchaea such as Hfx. mediterranei and $H f x$. volcanii have a proteinaceous S-layer anchored to the microorganism's surface that functions as a protective coat, molecular sieve, molecule and ion traps, as well as perform roles in surface recognition and cell shape maintenance [48]. The S-layer constitute the only cell envelope structure in haloarchaea, with the exception of halococci and certain strains of Haloquadratum walsbyi. The S-layer lattice type in halophilic archaea is hexagonal, its centerto-center spacing distance value is between 12 and $16 \mathrm{~nm}$ (similar to that detected in most methanogens), and it presents an acidic amino acid composition and glycosylation [33]. The exposed glycan chains influence the surface roughness of the cell on the nanometer scale and cause the formation of a lubrication hydration layer. The presence of the Slayer as the only cell envelope structure in haloarchaea may facilitate the incorporation of dyes as compared to other archaea with an S-layer in addition to the cell wall. However, haloarchaea exhibit optimal growth in salt concentrations approaching the saturation point; the high ionic strength of the medium is inappropriate for conventional antibodies and dyes, and salt crystals interfere with microscopic observation of cells, especially when no staining method is used as demonstrated in the phase contrast images of Hfx. mediterranei. In addition, the high intracellular content of potassium ions to counterbalance the high sodium concentration may complicate staining [49].

Most of the published works use transmission electron microscopy (TEM) to visualize PHA granules in haloarchaea $[9,10,23]$. As shown in Figure 3, TEM is an excellent tool for imaging PHA granules and characterizing their size and shape [27]. However, it requires working with fixed cells, and is a time-consuming technique comprising many steps (fixation with several fixation agents, dehydration, embedding, and ultrathin section cutting) that require highly experienced staff, in addition to the higher cost of the technique as compared to fluorescence staining. Legat et al. (2010) reported for the first time the use of three dyes (Sudan black, Nile blue A, and Nile red) for the easy and quick identification of PHA-producing haloarchaea, thus demonstrating the permeability of the S-layer and the cell wall to these dyes and allowing the identification of a new PHA-producing Halococcus species [31]. Sudan black B and Nile blue dyes were employed to stain fixed cells, and PHA granules were subsequently observed by optical and fluorescence microscopy, respectively. They also observed a diffuse staining, which roughly delineated the cell morphology and could be attributed to other lipid structures such as membranes or haloarchaeal Slayers [34]. Nile red staining was used for the identification of PHA-producing colonies growing on agar plates by UV light exposure, showing the presence of fluorescent colonies in many haloarchaeal species [31]. Mahansaria et al. (2015) also reported the use of Nile red in the staining of growing colonies for the identification of PHA producers among halobacteria and haloarchaea, and in the visualization of fluorescence colonies 
with a UV transilluminator in addition to a polymerase chain reaction-based screening method, through the amplification of a conserved region of the Class III PHA synthase $(p h a C)$ gene [32]. Both works reported the use of Nile red to identify PHA-producing microorganisms; stained cells were not observed with fluorescence microscopy, but with a UV transilluminator. Due to the lipophilic nature of this dye, it can bind to other lipid inclusions, membranes, or haloarchaeal cell envelopes and falsely depict the organism such as a PHA producer upon its exposure to UV light.

Nile red staining can be performed in living cells under growing conditions, allowing for the visualization of PHAs as fluorescent red granules. In haloarchaea, the presence of salt crystals in the medium, even after washing the cells, hinders the identification of cells by confocal microscopy and the co-localization of Nile red-stained PHA granules inside the cytoplasm of cells, as shown in Figures 1 and 2. Moreover, due to its lipophilic nature, Nile red can bind unspecifically to other cell structures [31], making it important to use an additional fluorescent dye to corroborate the localization of PHA granules. In this study, we are presented with the first visualization of PHA granules in unfixed cells by confocal microscopy, as well as the use of a second fluorescence staining with the fluorescent cyanine dye SYBR Green [50] in providing a rapid and easy method for the identification of PHA granules (Figure 4). This double-staining method with Nile red and SYBR Green in Hfx. mediterranei is proven to be an appropriate way to co-localize PHA granules inside the cytoplasm of cells by confocal microscopy, merging both channels of fluorescence and allowing the analysis of PHA granule size (Figure 4). This method demonstrates that these dyes are compatible with media of high ionic strength. This involves a faster, simpler, and more economical procedure for identifying PHAs. The promising future of these biopolymers sheds light on a global problematic, making the study of their potential indispensable in developing more sustainable production methods.

\section{Conclusions}

This work optimizes a new, quick, and cheap method that uses Nile red and SYBR Green to detect PHA production by haloarchaea and to quantify the mean size of PHA granules in living cells, thus demonstrating the utility of this method in the Archaea domain. This involves a simpler, more affordable, and faster procedure for identifying PHAs during a period wherein the urge to replace conventional oil-based plastics is of international interest. Consequently, this aids in boosting the development of archaeal cell factories as promising and sustainable biotechnological platforms for PHA production.

Author Contributions: V.C. and S.G.-C. carried out most of the experimental work and helped in the design of the study. L.S.-C. assisted in microorganism cultures and participated in the writing of the manuscript. V.C. was involved in data analyses. F.M., C.F.-A., and C.P. contributed to writing and final review editing. V.C. and R.M.M.-E. were involved in the conceptualization, interpretation of the data, project administration, funding acquisition, and wrote the final draft. All authors have read and agreed to the published version of the manuscript.

Funding: This work was funded by a research grant from Instituto de Fomento de la Region de Murcia (INFO), Spain (2020.08.CT01.0039) and the University of Alicante (VIGROB-309).

Institutional Review Board Statement: Not applicable.

Informed Consent Statement: Not applicable.

Data Availability Statement: Not applicable.

Conflicts of Interest: The authors declare no conflict of interest.

\section{References}

1. Obruca, S.; Sedlacek, P.; Koller, M.; Kucera, D.; Pernicova, I. Involvement of polyhydroxyalkanoates in stress resistance of microbial cells: Biotechnological consequences and applications. Biotechnol. Adv. 2018, 36, 856-870. [CrossRef] [PubMed]

2. Koller, M.; Obruca, S.; Pernicova, I.; Braunegg, G. Physiological, kinetic, and process engineering aspects of polyhydroxyalkanoate biosynthesis by extremophiles. Polyhydroxyalkanoates Biosynth. Chem. Struct. Appl. 2018, 2013, 1-70. 
3. Bugnicourt, E.; Cinelli, P.; Lazzeri, A.; Alvarez, V. Polyhydroxyalkanoate (PHA): Review of synthesis, characteristics, processing and potential applications in packaging. Express Polym. Lett. 2014, 8, 791-808. [CrossRef]

4. Tarrahi, R.; Fathi, Z.; Seydibeyoğlu, M.Ö.; Doustkhah, E.; Khataee, A. Polyhydroxyalkanoates (PHA): From production to nanoarchitecture. Int. J. Biol. Macromol. 2020, 146, 596-619. [CrossRef]

5. Oren, A. Industrial and environmental applications of halophilic microorganisms. Environ. Technol. 2010, 31, 825-834. [CrossRef]

6. Pfeifer, K.; Ergal, İ.; Koller, M.; Basen, M.; Schuster, B.; Rittmann, S.K.M.R. Archaea Biotechnology. Biotechnol. Adv. 2020. [CrossRef]

7. Giani, M.; Garbayo, I.; Vílchez, C.; Martínez-Espinosa, R.M. Haloarchaeal carotenoids: Healthy novel compounds from extreme environments. Mar. Drugs 2019, 17, 524. [CrossRef] [PubMed]

8. Patel, G.B.; Sprott, G.D. Archaeobacterial ether lipid liposomes (archaeosomes) as novel vaccine and drug delivery systems. Crit. Rev. Biotechnol. 1999, 19, 317-357. [CrossRef] [PubMed]

9. DasSarma, S.; DasSarma, P. Halophiles and their enzymes: Negativity put to good use. Curr. Opin. Microbiol. 2015, 25, 120-126. [CrossRef] [PubMed]

10. Raho, S.; Carofiglio, V.E.; Montemurro, M.; Miceli, V.; Centrone, D.; Stufano, P.; Schioppa, M.; Pontonio, E.; Rizzello, C.G. Production of the polyhydroxyalkanoate PHBV from ricotta cheese exhausted whey by Haloferax mediterranei fermentation. Foods 2020, 9, 1459. [CrossRef]

11. Ferre-Guell, A.; Winterburn, J. Biosynthesis and Characterization of Polyhydroxyalkanoates with Controlled Composition and Microstructure. Biomacromolecules 2018, 19, 996-1005. [CrossRef]

12. Alsafadi, D.; Ibrahim, M.I.; Alamry, K.A.; Hussein, M.A.; Mansour, A. Utilizing the crop waste of date palm fruit to biosynthesize polyhydroxyalkanoate bioplastics with favorable properties. Sci. Total Environ. 2020, 737, 139716. [CrossRef]

13. Simó-Cabrera, L.; García-Chumillas, S.; Hagagy, N.; Saddiq, A.; Tag, H.; Selim, S.; AbdElgawad, H.; Arribas Agüero, A.; Monzó Sánchez, F.; Cánovas, V.; et al. Haloarchaea as Cell Factories to Produce Bioplastics. Mar. Drugs 2021, 19. [CrossRef]

14. Wang, K.; Zhang, R. Production of Polyhydroxyalkanoates (PHA) by Haloferax mediterranei from food waste derived nutrients for biodegradable plastic applications. J. Microbiol. Biotechnol. 2021, 31, 338-347. [CrossRef]

15. Mitra, R.; Xu, T.; Xiang, H.; Han, J. Current Developments on Polyhydroxyalkanoates Synthesis by Using Halophiles as a Promising Cell Factory. Microb. Cell Fact. 2020, 19, 1-30. [CrossRef]

16. Koller, M. Polyhydroxyalkanoate biosynthesis at the edge of water activitiy-haloarchaea as biopolyester factories. Bioengineering 2019, 6, 34. [CrossRef]

17. Lu, Q.; Han, J.; Zhou, L.; Zhou, J.; Xiang, H. Genetic and Biochemical Characterization of the Poly(3-Hydroxybutyrate-co-3Hydroxyvalerate) Synthase in Haloferax mediterranei. J. Bacteriol. 2008, 190, 4173-4180. [CrossRef] [PubMed]

18. Cai, S.; Cai, L.; Liu, H.; Liu, X.; Han, J.; Zhou, J.; Xiang, H. Identification of the haloarchaeal phasin (PhaP) that functions in polyhydroxyalkanoate accumulation and granule formation in Haloferax mediterranei. Appl. Environ. Microbiol. 2012, 78, $1946-1952$. [CrossRef] [PubMed]

19. Koller, M. Recycling of waste streams of the biotechnological poly(hydroxyalkanoate) production by Haloferax mediterranei on whey. Int. J. Polym. Sci. 2015, 2015. [CrossRef]

20. Beltrán-Sanahuja, A.; Casado-Coy, N.; Simó-Cabrera, L.; Sanz-Lázaro, C. Monitoring polymer degradation under different conditions in the marine environment. Environ. Pollut. 2020, 259, 113836. [CrossRef] [PubMed]

21. Gong, J.; Xie, P. Research progress in sources, analytical methods, eco-environmental effects, and control measures of microplastics. Chemosphere 2020, 254, 126790. [CrossRef]

22. Koller, M.; Rodríguez-Contreras, A. Techniques for tracing PHA-producing organisms and for qualitative and quantitative analysis of intra-and extracellular PHA. Life Sci. 2015, 15, 558-581. [CrossRef]

23. Wei, Y.H.; Chen, W.C.; Huang, C.K.; Wu, H.S.; Sun, Y.M.; Lo, C.W.; Janarthanan, O.M. Screening and evaluation of polyhydroxybutyrate-producing strains from indigenous isolate Cupriavidus taiwanensis strains. Int. J. Mol. Sci. 2011, 12, 252-265. [CrossRef]

24. Spiekermann, P.; Rehm, B.H.A.; Kalscheuer, R.; Baumeister, D.; Steinbüchel, A. A sensitive, viable-colony staining method using Nile red for direct screening of bacteria that accumulate polyhydroxyalkanoic acids and other lipid storage compounds. Arch. Microbiol. 1999, 171, 73-80. [CrossRef] [PubMed]

25. Ostle, A.G.; Holt, J.G. Nile Blue A as a Fluorescent Stain for Poly-3-Hydroxybutyrate. Appl. Environ. Microbiol. 1982, 44, 234-244. [CrossRef]

26. Juengert, J.; Bresan, S.; Jendrossek, D. Determination of Polyhydroxybutyrate (PHB) Content in Ralstonia eutropha Using Gas Chromatography and Nile Red Staining. Bio-Protocol. 2018, 8, 1-15. [CrossRef]

27. Koller, M.; Atlić, A.; Dias, M.; Reiterer, A.; Braunegg, G. Microbial PHA Production from Waste Raw Materials. In Plastics from Bacteria: Natural Functions and Applications; Chen, G.-Q., Ed.; Springer: Berlin/Heidelberg, Germany, 2010; Volume 14, pp. 85-119.

28. Elain, A.; Le Fellic, M.; Corre, Y.M.; Le Grand, A.; Le Tilly, V.; Audic, J.L.; Bruzaud, S. Rapid and qualitative fluorescence-based method for the assessment of PHA production in marine bacteria during batch culture. World J. Microbiol. Biotechnol. 2015, 31, 1555-1563. [CrossRef] [PubMed]

29. Mesquita, D.P.; Amaral, A.L.; Leal, C.; Oehmen, A.; Reis, M.A.M.; Ferreira, E.C. Polyhydroxyalkanoate granules quantification in mixed microbial cultures using image analysis: Sudan Black B versus Nile Blue A staining. Anal. Chim. Acta 2015, 865, 8-15. [CrossRef] 
30. Martinez, V.; Henary, M. Nile Red and Nile Blue: Applications and Syntheses of Structural Analogues. Chem. A Eur. J. 2016, 22, 13764-13782. [CrossRef] [PubMed]

31. Legat, A.; Gruber, C.; Zangger, K.; Wanner, G.; Stan-Lotter, H. Identification of polyhydroxyalkanoates in Halococcus and other haloarchaeal species. Appl. Microbiol. Biotechnol. 2010, 87, 1119-1127. [CrossRef]

32. Mahansaria, R.; Choudhury, J.D.; Mukherjee, J. Polymerase chain reaction-based screening method applicable universally to environmental haloarchaea and halobacteria for identifying polyhydroxyalkanoate producers among them. Extremophiles 2015, 19, 1041-1054. [CrossRef]

33. Rodrigues-Oliveira, T.; Belmok, A.; Vasconcellos, D.; Schuster, B.; Kyaw, C.M. Archaeal S-layers: Overview and current state of the art. Front. Microbiol. 2017, 8. [CrossRef] [PubMed]

34. Sprott, G.D. Structures of archaebacterial membrane lipids. J. Bioenerg. Biomembr. 1992, 24, 555-566. [CrossRef] [PubMed]

35. Elferink, M.G.L.; de Wit, J.G.; Driessen, A.J.M.; Konings, W.N. Stability and proton-permeability of liposomes composed of archaeal tetraether lipids. BBA-Biomembr. 1994, 1193, 247-254. [CrossRef]

36. Singer, V.L.; Lawlor, T.E.; Yue, S. Comparison of SYBR ${ }^{\circledR}$ Green I nucleic acid gel stain mutagenicity and ethidium bromide mutagenicity in the Salmonella/mammalian microsome reverse mutation assay (Ames test). Mutat. Res.-Genet. Toxicol. Environ. Mutagen. 1999, 439, 37-47. [CrossRef]

37. Martens-Habbena, W.; Sass, H. Sensitive Determination of Microbial Growth by Nucleic Acid Staining in Aqueous Suspension. Appl. Environ. Microbiol. 2006, 72, 87-95. [CrossRef]

38. Rodriguez-Valera, F.; Ruiz-Berraquero, F.; Ramos-Cormenzana, A. Behaviour of mixed populations of halophilic bacteria in continuous cultures. Can. J. Microbiol. 1980, 26, 1259-1263. [CrossRef] [PubMed]

39. Lillo, J.G.; Rodriguez-Valera, F. Effects of Culture Conditions on Poly(beta-Hydroxybutyric Acid) Production by Haloferax mediterranei. Appl. Environ. Microbiol. 1990, 56, 2517-2521. [CrossRef]

40. Tian, J.; Sinskey, A.J.; Stubbe, J.; Tian, J.; He, A.; Lawrence, A.; Liu, P.; Watson, N.; Sinskey, A.J.; Stubbe, J. Kinetic Studies of Polyhydroxybutyrate Granule Formation in Wautersia eutropha H16 by Transmission Electron Microscopy. J. Bacteriol. 2005, 187, 3814-3824. [CrossRef]

41. Martínez-Gutiérrez, C.A.; Latisnere-Barragán, H.; García-Maldonado, J.Q.; López-Cortés, A. Screening of polyhydroxyalkanoateproducing bacteria and PhaC-encoding genes in two hypersaline microbial mats from Guerrero Negro, Baja California Sur, Mexico. PeerJ 2018, 6, e4780. [CrossRef]

42. Balakrishna Pillai, A.; Jaya Kumar, A.; Kumarapillai, H. Enhanced production of poly(3-hydroxybutyrate) in recombinant Escherichia coli and EDTA-microwave-assisted cell lysis for polymer recovery. AMB Express 2018, 8. [CrossRef] [PubMed]

43. Bai, J.; Dai, J.; Li, G. Electrospun composites of PHBV/pearl powder for bone repairing. Prog. Nat. Sci. Mater. Int. 2015, 25, 327-333. [CrossRef]

44. Don, T.M.; Chen, C.W.; Chan, T.H. Preparation and characterization of poly(hydroxyalkanoate) from the fermentation of Haloferax mediterranei. J. Biomater. Sci. Polym. Ed. 2006, 17, 1425-1438. [CrossRef]

45. Melanie, S.; Winterburn, J.B.; Devianto, H. Production of Biopolymer Polyhydroxyalkanoates (PHA) by Extreme Halophilic Marine Archaea Haloferax mediterranei in Medium with Varying Phosphorus Concentration. J. Eng. Technol. Sci. 2018, 50, 255-271. [CrossRef]

46. Koller, M.; Chiellini, E.; Braunegg, G. Study on the production and re-use of poly(3-hydroxybutyrate-co-3-hydroxyvalerate) and extracellular polysaccharide by the archaeon Haloferax mediterranei strain DSM 1411. Chem. Biochem. Eng. Q. 2015, 29, 87-98. [CrossRef]

47. Zheng, Y.; Chen, J.C.; Ma, Y.M.; Chen, G.Q. Engineering biosynthesis of polyhydroxyalkanoates (PHA) for diversity and cost reduction. Metab. Eng. 2020, 58, 82-93. [CrossRef]

48. Sleytr, U.B.; Schuster, B.; Egelseer, E.-M.; Pum, D. S-layers: Principles and applications. FEMS Microbiol. Rev. 2014, 38, 823-864. [CrossRef] [PubMed]

49. Oren, A. Microbial life at high salt concentrations: Phylogenetic and metabolic diversity. Saline Syst. 2008, 4. [CrossRef] [PubMed]

50. Dragan, A.I.; Pavlovic, R.; McGivney, J.B.; Casas-Finet, J.R.; Bishop, E.S.; Strouse, R.J.; Schenerman, M.A.; Geddes, C.D. SYBR Green I: Fluorescence properties and interaction with DNA. J. Fluoresc. 2012, 22, 1189-1199. [CrossRef] 